\title{
JULIO ORTEGA: PRÁCTICAS DE AGREGACIÓN
}

\author{
Diamela Eltit
}

En estas páginas se identifican los dispositivos de activismo y teoría que Julio Ortega, escritor y ensayista peruano, moviliza en su obra crítica para construir espacios comunitarios nuevos en el campo de la literatura latinoamericana actual.

\section{L}

os homenajes son maravillosos pero también, en cierto sentido, ambiguos. Recuerdo en forma vívida los homenajes realizados en Chile — de manera simultánea- a Nicanor Parra quien cumplía 80 y a José Donoso en sus 70 años. Ambos concurrieron a recibir diplomas y medallas en una ceremonia que convocó a un número considerable de artistas, escritores, intelectuales y personajes pertenecientes al mundo político. Estoy segura de que existía una emoción sincera al ver reunidos a dos importantísimos representantes de la literatura nacional. Más aún si se considera que toda-

Diamela Eltit (Santiago de Chile, 1949). Escritora y profesora de literatura. Autora, entre otras, de las novelas Lumpérica (1983), Por la Patria (1986), El Cuarto Mundo (1988), El Padre Mío (1989), Vaca Sagrada (1991), Infarto del Alma (1994), Los Vigilantes (Premio José Nuez Martín 1995), Los Trabajadores de la Muerte (1998), Mano de Obra (2002) Puño y Letra y Jamás el Fuego Nunca (2007), de reciente aparición.

* Texto leído en el homenaje que la Cámara Peruana del Libro le rindió a Julio Ortega en Lima, en agosto de 2008.

Estudios Públicos, 111 (invierno 2008). 
vía daban vueltas y vueltas de manera nítida los años terribles de la dictadura y, en ese contexto, el reconocimiento a los dos autores era el mejor signo de un cambio en los registros sociales y culturales del país.

No se trataba de una ceremonia académica sino oficial, encabezada por autoridades pertenecientes al Ministerio de Educación y representantes de la reciente estructura cultural que implementaba el primer gobierno de la Concertación. En ese sentido era un festejo cruzado por discursos más bien elogiosos que apuntaban a remarcar las trayectorias de los escritores chilenos. Quizás por la generalidad de los discursos y por el carácter marcadamente social del encuentro, es que las apreciaciones de los asistentes se centraron en las edades de los festejados, en la apariencia de sus apariencias.

El público celebraba la juventud inamovible de Nicanor Parra, su estado ultra atlético que contrastaba con la figura más bien sedentaria del querido José Donoso. Porque en verdad Nicanor atravesó literalmente corriendo el espacio que lo separaba del pódium para recibir sus condecoraciones y diplomas y en su discurso acudió a la ironía párrica o parraniana que lo caracteriza. En cambio José Donoso, de manera pausada y con un discurso más entrecortado, se hizo parte de la ceremonia. Y eso que Nicanor tiene 80 y Donoso sólo 70, decían cuando terminaron los festejos, durante el cóctel que coronaba la reunión de ese mediodía. O bien señalaban: realmente Nicanor Parra parece un adolescente. Comentarios similares se repetían una y otra vez en cada uno de los grupos que frecuenté en esa oportunidad.

Mientras me devolvía a mi casa sentí una especie de culpa ante el hecho de que en esa ocasión única no hubiésemos hablado de la obra y de las estéticas de nuestros respetados escritores y no únicamente del tiempo — digamos - corporal. Esa misma noche mientras veía el noticiero se destacó la imagen de un hombre que había cumplido 105 años y cuyo gran mérito, por no decir milagro, consistía en que se podía levantar sin ayuda de su silla, cuestión que hizo un par de veces ante las cámaras y que fue aplaudido por los familiares que lo acompañaban en su celebración y también recibió comentarios elogiosos y entusiastas del conductor del noticiario. Volví a pensar en Nicanor Parra y en José Donoso, en el homenaje tan prestigioso pero, a la vez, amenazante, porque ese homenaje inolvidable y más que merecido daba cuenta también de una aguda y riesgosa sanción al físico del homenajeado.

Pero, Julio Ortega, afortunadamente para él, está en la orilla párrica o parriana, aunque, claro, su homenaje lo encuentra no sólo en plena vigencia 
intelectual sino en años aún mozos que le van a permitir tener una larga experiencia cuando se precipiten los múltiples homenajes del porvenir.

Es un honor para mí la oportunidad de participar en esta reunión con que la Cámara Peruana del Libro le rinde un merecido reconocimiento a uno de los intelectuales más importantes de Latinoamérica y en el plano personal a un amigo entrañable en este mundo empecinadamente "ancho y ajeno".

Para referirme a Julio Ortega quiero invocar una imagen en cierto modo discutida o desechada en este presente cruzado por pasiones y pulsiones individualistas, me refiero al concepto de comunidad. Pienso que su transcurso cultural y vital apunta a ese horizonte, a pensar y construir comunidades literarias fundadas en la circulación de escrituras, de cuerpos, de poéticas.

Desde la inteligencia más aguda y agitada, Julio Ortega conceptualiza — por usar una expresión — una literatura líquida o transatlántica o móvil pero a la vez esmeradamente territorializada. Es ese dispositivo exacto y paradójico el que me hace pensar en una comunidad que se organiza desde una geografía vibrantemente inacabada, en constante agregación. En ese sentido, pienso que su quehacer ilumina un proyecto único pues pertenece a la esfera de lo que podría ser considerado como el acopio de una "virtualidad concreta" que se articula desde una perspectiva, digamos, global pero sin desconocer una realidad o una calidad híper localista.

De manera obstinada y paciente a la vez, Julio Ortega “escucha” a las literaturas, les otorga un espacio a cada una de ellas, transformando así su quehacer intelectual (normalmente asociado a las academias y al fetichizado lugar solitario del pensamiento) en una práctica cultural "activa” que apunta a la configuración de identidades literarias que se movilizan, se expanden, se repiensan o se renuevan en flujos colectivos pero que no renuncian a las indispensables individualidades. De esa manera ha originado una de las experiencias críticas vivas o vitales más notables, una experiencia que no se funda en los tradicionales "grupos” marcados por elementos biográficos y sus siempre complejos vaivenes, sino que se articula en arquitecturas de sentido. Hacia esa arquitectura confluyen sus libros, antologías, ensayos literarios, artículos en periódicos, congresos, mesas redondas, proyectos de intercambio de narradores jóvenes y reuniones en ferias de libro. Una experiencia que porta una forma de transnacionalismo no imperial que busca disponer y no imponer letras de diversas procedencias, tiempos, territorios, imaginarios. 
En una determinada perspectiva no necesariamente lineal, la tarea crítica emprendida por Julio Ortega me recuerda ciertos parámetros adoptados por el sociólogo Pierre Bourdieu quien fuera descrito como el último intelectual francés comprometido con su tiempo (participó en marchas, huelgas, dirigió una serie de entrevistas a habitantes de barrios obreros, entre otras actividades). Por supuesto en su propio registro y desde un lugar otro, Julio Ortega mantiene una interlocución constante con las escrituras más consolidadas e inscritas de la lengua española actual, sólo por nombrar algunos autores demasiado prestigiosos pienso en Carlos Fuentes o Alfredo Bryce Echeñique, pero, y esto es lo sorprendente y político para mí, su mapa construye relaciones igualmente intensas en el otro lado del glamour, con obras y autores más descentrados o bien definitivamente locales que habitan en las orillas también lúcidas y brillantes del trazado que se propuso organizar.

Recuerdo de manera especial uno de sus viajes a Chile, el más prolongado que realizó donde se dio el tiempo de escuchar, reunirse, leer, recibir a cada uno de los escritores que se le acercaron con sus siempre urgentes manuscritos. Los poetas numerosos y definitivamente apasionados encontraron un espacio, una voz, un estatuto, un gesto indispensable para verificarse a ellos mismos a través de una persona ya muy consagrada que les decía que sí, que sí. Y en el acto ético de “escuchar”, en el sentido más intenso que adquiere esta palabra, los validaba en el oficio minoritario y siempre demente de escribir. En mi ya larga pertenencia en la esfera literaria, nunca había visto ni he vuelto a ver una actitud semejante de compromiso y comprensión ante la necesidad de interlocución de un grupo de narradores y poetas chilenos.

Pero, también durante esa visita y en una reunión académica que participé, pude observar cómo Julio Ortega acudía a la estructura del ayllu para argumentar su intervención. Esa práctica organizativa de la cultura prehispánica, esa política me ronda ahora para pensar en la comunidad que nos propone el crítico y escritor peruano.

Desde luego el ayllu funcionaba en su discurso como la alegoría de un modo de habitar posible, recorrido por diversos espacios que no necesariamente estaban subordinados por jerarquías tradicionales sino sostenidos en hilos estratégicos. Éste me resulta el modelo más próximo para comprender el trazado cultural que caracteriza el trabajo de Julio Ortega. Desde el ayllu como sustento simbólico y como utopía de la sobrevivencia se puede pensar en esta comunidad fundada en espirales donde los tiempos y los espacios transcurren y ocurren de maneras diferenciadas pero están unidos por la comunidad de un hito identitario: la literatura. 
En ese sentido, desde la academia y con el capital simbólico (como diría Bourdieu) de saberes extremadamente calificados, su proyecto consiste en el traspaso en primer término de sus propias fronteras - la academia misma - para ingresar activamente en los espacios más contingentes en que se cursan y construyen las inflexiones, marcas, pasiones, versiones y aversiones del ámbito literario. En este viaje de carácter semi mítico o ficcional o memorioso por congresos, editoriales, artículos, bares, hoteles, museos, centros de trabajo, Julio Ortega va también organizando un corpus de lecturas y espacios de escrituras que contradicen los dictámenes más efímeros del libre mercado y sus vaivenes.

En este escenario que intento configurar, el trabajo crítico de Julio Ortega genera una “tensión” activa, móvil, incapturable, imposible de cooptar por las fuerzas más ligeras que manejan una parte del tramado literario. Quizás esa movilidad, ese trazado siempre efervescente y en curso que nos propone Julio Ortega, se constituya en la mejor manera de pensar el mundo del arte y de la literatura en general. Me parece así en la medida que existe en ese procedimiento un activismo que por su comunitarismo resulta definitivamente incluyente frente a un estadio cultural que más bien tiende a la exclusión puesto que exalta de manera abusiva la noción de ránquines rígidos y de éxitos bien remunerados.

Desde luego la movilidad, la rapidez, el vértigo, están asociados a la realidad globalizada, pero esas energías tecnológicas hoy también alcanzan a los cuerpos y se verifican en la explosión migratoria. A la manera de una bandada de pájaros que buscan sobrevivir a los climas adversos y vuelan distancias inauditas para protegerse, los sujetos cruzan las fronteras buscando mejores condiciones donde cursar sus existencias. Cientos de miles de personas, en distintos puntos del planeta, emprenden viajes sin retorno para volver a empezar en algún punto del globo que, más allá de toda angustia, hostilidad o extrañeza, terminará por pertenecerles.

La migración forma parte de la historia humana o quizás lo más acertado es afirmar que la historia humana se articula desde el desplazamiento. Desde luego en el viaje migratorio se funden y confunden la urgencia y la esperanza, el malestar y la esperanza, la persecución y la esperanza e incluso la barrera que divide la vida de la muerte. Los siglos y sus signos han intensificado o controlado estos movimientos humanos, pero cada época nos habla de la extranjería y de la fascinación que provocan las fronteras.

Primero la pintura, después la fotografía y más adelante el cine, se transformaron en los materiales y las técnicas que hicieron visibles los pai- 
sajes. La pantalla cinematográfica mostró el poderío de los rascacielos o el romanticismo del Mediterráneo en calma. París, Londres o Nueva York refulgieron como postales animadas y los imaginarios sociales pudieron sentir que esos espacios, en cierto modo, habitaban sus propios territorios (mentales). Pero también esa mirada se volvió sobre sí misma e idealizó el lugar propio y no ocultó su crítica hacia las metrópolis.

Los artistas, los intelectuales y los escritores latinoamericanos viajeros "por naturaleza" tuvieron que enfrentarse en la segunda mitad del siglo XX a este dilema ¿dónde vivir? O dicho de otra manera, ¿¿cuál era la relación entre escritura y lugar de producción?

José María Arguedas y Julio Cortázar polarizaron sus discusiones ¿dónde radicaba el lugar de la escritura? ¿En el tramado simbólico o en el suelo material de la experiencia? Se abrió entonces una pregunta interesante y, aún más, apabullante. Más que una respuesta o una "verdad verdadera" lo más pertinente resultaba establecer esa pregunta (sin respuesta) para permitir el flujo amplio y pasional de ese específico debate.

Pero la velocidad tecnológica y la democratización de las comunicaciones han modificado las reglas del juego entre los cuerpos y los territorios. El mundo en su máxima virtualidad pudo ser visible desde todos los ángulos, se ha vuelto completamente trasparente como si el ojo compartiera una complicidad con los numerosos satélites espías que pueblan la estratósfera.

Tenemos que ser absolutamente modernos, proclamó Rimbaud en la ya antigua era de la revolución industrial. No sólo el Mac Donald's o la comida china han mostrado sus marcas imperiales en cada uno de los centros comerciales y de las ciudades de Latinoamérica sino que los cibercafés parecen reemplazar a la continuidad y el número de las antiguas cantinas. Los cuerpos se han sentado ante las pantallas a navegar por un precio asequible, navegan entre continentes sin mayores riesgos, navegan por los espacios del saber, de la música, de la conversación, del juego de las identidades, de la compra o el porno. Las direcciones cambian velozmente, de manera literal las noticias vuelan.

¿Quién podría interrogar hoy el viaje? Cómo pensar entonces lo local y lo deslocalizado. Pienso que en este marco, en la política tecnológica que marca este presente, la figura cultural de Julio Ortega resulta ejemplar — “un modelo para armar” como diría Julio Cortázar — para pensar de manera más compleja la relación entre viaje y literatura. Me refiero al polémico viaje del siglo XX y la nueva navegación que se intensifica en el siglo XXI. 
El viaje literario del siglo XX fue una constante pero también no estuvo exento de polémicas. Más adelante, las sucesivas dictaduras en el cono sur del continente motivaron el viaje político multitudinario. El exilio se estableció y ocupó el "mundo” y así el sur del Continente se abrió al cosmopolitismo.

Julio Ortega salió de Perú, invitado a enseñar en Estados Unidos y se estableció allí de manera permanente, pero —y esto es lo que me parece fundamental — viajó para construir una nueva posibilidad de latinoamericanismo, una forma, flexible y modular. Porque aunque radica en Estados Unidos, habría que pensar en Ortega como un "ciudadano de las letras hispanoamericanas" que desde otras tierras busca re-bolivarizar espacios, franjas, sentidos.

Estoy pensando en la relación más concreta entre literatura y globalización, pienso que más allá de las extraordinarias posibilidades abiertas por el ciber espacio que requiere de cibernautas especializados, el campo literario permanece más o menos inalterado desde que se produjera el explosivo boom que consagró e internacionalizó a un grupo de destacados escritores. En ese sentido y desde esa plataforma estimo que la globalización en el campo literario no ha evolucionado al ritmo de otros digamos — bienes de consumo- en la medida que las editoriales locales no cuentan con los mecanismos para cruzar las fronteras ni los textos (en su más amplia mayoría) alcanzan la esfera de las traducciones.

Pero también es necesario reconocer que existe un no saber que puede resultar apasionante, quiero decir el terreno del encuentro de ese particular libro único obtenido de manera circunstancial y que, sin embargo, abre un pedazo de mundo que acompaña e ilumina el quehacer literario. Pero, claro, más allá o más acá de esta posibilidad estética, que le pertenece al campo de los lectores especializados, lo más importante sigue siendo la fragmentación política que circunscribe la circulación de las estéticas a los poderes trasnacionales.

Precisamente en ese hueco o vacío se inserta la intervención crítica de Julio Ortega en los espacios cultuales. Allí donde falla la relación entre política y cultura, en la grieta insalvable que se abre entre literatura y capital o en el sitio más intenso del deseo de estéticas contra el pragmatismo que otorga el deseo de cosmética, irrumpe esa sutura que la práctica de Julio Ortega ha inscrito y escrito para el mundo latinoamericano.

No puedo dejar de señalar aquí una característica más que me parece francamente excepcional, Julio Ortega construye territorios de escrituras hasta donde llegan escritores y escritoras. 
Quizás una de las falencias más lamentables del mundo literario latinoamericano sea su carácter ensimismado en una masculinidad, como habría dicho José Donoso: inbunche, oclusiva, plegada sobre sí misma. Desde luego, la dedicación a la escritura porta una forma de épica, alude a una hazaña por los considerables obstáculos que acechan y cercan ese hacer y, por otra parte, la épica en su sentido más guerrero e histórico ha estado ligada a lo masculino. También es rigurosamente efectivo que las grandes batallas y enfrentamientos literarios se han producido entre hombres y forman parte del mito, del relato, del chisme cultural con el que la literatura se exalta y se protege a sí misma.

Y por supuesto que la leyenda literaria pone a la mujer mayoritariamente en el lugar interesante aunque un poco cursi de la musa o bien en el de la viuda que está allí para obstaculizar, casi como venganza póstuma, la gran obra del que fuera su marido. Y la mujer escritora, en muchos casos, es omitida o leída desde la perspectiva de la histeria para justificar así su falta de historia. Salvo excepciones —y esto no podría discutirse - el espacio literario latinoamericano se pacta y se repacta en los terrenos masculinos.

Desde luego, la literatura reproduce la asimetría que caracteriza a todos y cada uno de los trazados sociales. Pero, también (lo señalo como juego lingüístico) hay que considerar que si aceptamos que la escritura es poder, es tan poderosa que tiene el poder de segmentarse a sí misma de acuerdo a la división matriz: masculino y femenino. Y allí entonces la escritura, en última instancia, mide su propio poder luchando contra sí misma otorgándole doble categoría a la letra.

Pero el trabajo de Julio Ortega apunta también a remodelar este duro frente y en su tarea inclusiva, que es central para ejercer la democracia (repartir, repactar los poderes), circulan en su imaginación literaria Margo Glantz, Matilde Sánchez, Ángeles Mastretta, Elena Poniatowska o Rosario Ferré, por nombrar a escritoras fundamentales. Y cómo no, a las escritoras jóvenes y sus producciones e imaginarios que harán posibles los haces literarios del porvenir.

Quiero arriesgarme y enunciar lo que podría un lugar común presumible y previsible en el marco de un homenaje. Sí, porque me arriesgo a afirmar que Julio Ortega es un intelectual excepcional. Su obra seduce por el nivel de una escritura sofisticadamente estética, exacta y allí están sus numerosos libros, desde La Contemplación y la Fiesta, en 1968 hasta hoy, para recordarnos que la crítica es no sólo una importante producción de sentido sino también una sed inconmensurable de estéticas. 
Y es excepcional porque su poder cultural lo ejerce desde una ética consistente hasta donde cita y convoca lo "uno" y lo otro, la doxa y lo heterodoxo en un trazado que re-une o re-hace el viaje entre el Pacífico hasta el Atlántico para promover políticamente nuevos y diversos órdenes estéticos que buscan evitar los naufragios y disminuir los ahogos.

Muchas gracias, Julio.

Palabras clave: literatura latinoamericana; crítica literaria; Julio Ortega. Recibido: septiembre de 2008; aceptado: octubre de 2008. 